\title{
Morphology of the immature stages of Panorpa qinlingensis (Mecoptera: Panorpidae) with notes on its biology
}

\author{
Li-jun Cai \& Bao-zhen Hua*
}

\begin{abstract}
Cai, L. J. \& Hua, B. Z. 2009: Morphology of the immature stages of Panorpa qinlingensis (Mecoptera: Panorpidae) with notes on its biology. - Entomol. Fennica 20: 215-224.

The scorpionfly Panorpa qinlingensis Chou \& Ran is described and illustrated in detail for its immature stages, including egg, larva, and pupa. The egg is oval with chorion decorated with irregular polygonal network. The larva is eruciform and peripneustic, bearing eight pairs of abdominal prolegs. A pair of prominent compound eyes are present on head. The first instar larva differs from later instars in possessing a prominent egg burster on frons and with clavate setae. The pupa is exarate and decticous, taking the shape of the adults. The scorpionfly is bivoltine, overwintering as prepupal stage in the soil. The durations of the egg, larval, and pupal stages are 5-9 d, 19-27 d, and 8-18 d respectively for the first generation. Adults emerge from mid May to early June and from late July to mid August in the Micang Mountain, central China.
\end{abstract}

\begin{abstract}
L. J. Cai, Key Laboratory of Plant Protection Resources and Pest Management, Ministry of Education, Shaanxi 712100,China; E-mail: cailj@nwsuaf.edu.cn

B. Z. Hua (*corresponding author), Entomological Museum, Northwest A\&F University, Yangling, Shaanxi 712100, China; E-mail: huabzh@nwsuaf.edu.cn
\end{abstract}

Received 29 September 2008, accepted 31 October 2008

\section{Introduction}

Considering their significance in the phylogeny of Hexapoda, an ironic fact is that the members of the order Mecoptera are rarely studied for their immature stages. Only several species of the genus Panorpa Linneaus are reported for their larvae and pupae in Europe (Brauer 1863, Shiperovitsch 1940), North America (Byers 1963, Mampe \& Neunzig 1965, Boese 1973), and Asia (Miyake 1912, Yie 1951), but few of them were studied morphologically in detail. More than 100 species of Panopa occur in China, but only seven species from Taiwan were described for their larvae and two species for their pupae (Yie 1951). Cai et al. (2006) very briefly reported the biology of Panorpa qinlingensis Chou \& Ran. Though a color plate for the eggs, larva, pupae as well as adults was provided, no detail description was made for the immature stages in Cai et al. (2006).

$P$. qinlingensis, originally described from the Qinling Mountains (Chou et al. 1981), was found to occur abundantly at the Micang Mountain in southwestern Shaanxi Province when we investigated the life history and biology of the scorpionfly from 2004 to 2005. All the immature stages of $P$. qinlingensis, including egg, larva and pupa, were successfully obtained through rearing and are described morphologically in this paper.

\section{Material and methods}

The adult scorpionflies of $P$. qinlingenis were captured by net and reared in the Liping National 

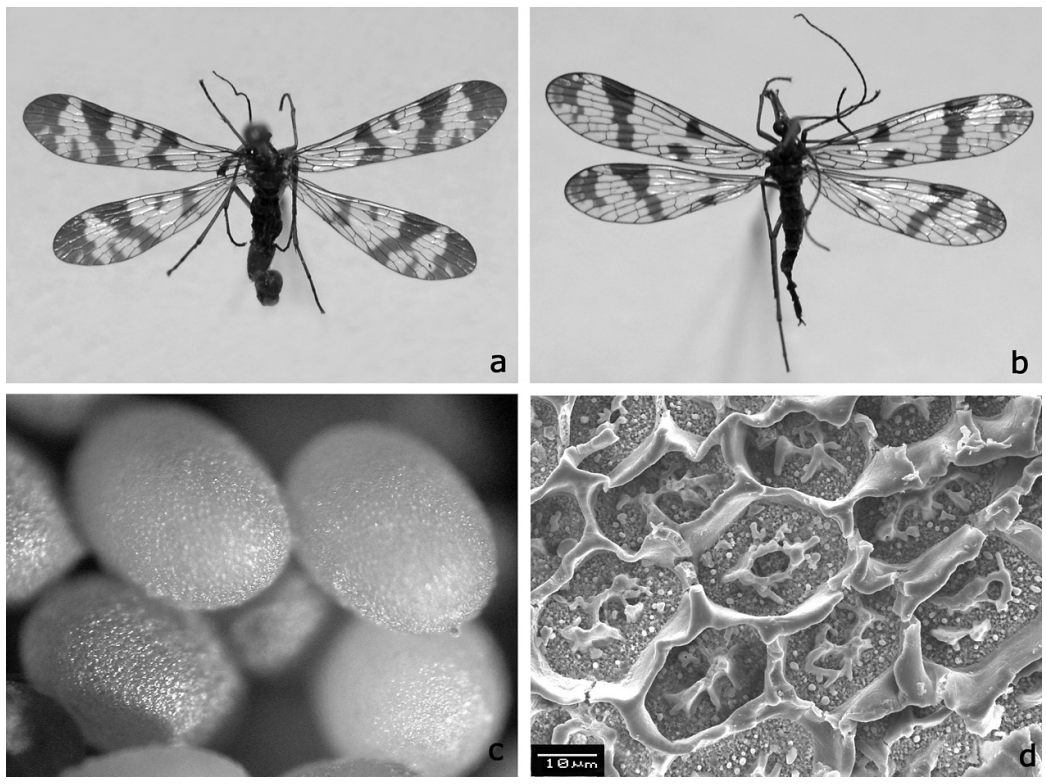

Fig. 1. Adults and eggs of Panorpa qinlingensis. - a. Male. - b. Female. - c. Eggs. - d. SEM of part chorion.

Forest Park, Nanzheng County, southwestern part of Shaanxi Province, from late July to early September in 2004, and from May to September in 2005, respectively. The adults were kept in screen-wire cages of $30 \mathrm{~cm}$ in height and $20 \mathrm{~cm}$ in diameter with a zipped gate. The cages were furnished with live pot-plants for the scorpionflies to rest and wet paper-tissue pads for drinking and humidity. Eggs, larvae, and pupae were incubated or reared in plastic containers with dampened pads of paper tissues. Freshly killed insects, including katydids, grasshoppers and caterpillars, were provided as food items for both adults and larvae. From 13 October 2004 to May 2005, the scorpionflies were reared in laboratory. The temperature was generally kept around $20^{\circ} \mathrm{C}$.

All the voucher specimens are preserved in $70 \%$ alcohol and deposited in the Entomological Museum, Northwest A\&F University, Yangling, Shaanxi, China [NWAU]. Observation and illustration were made under a Nikon Stereoscopic Zoom Microscope SMZ1500. The photographs were taken by the Nikon CoolPix5000 digital camera independently or attached to microscope.

For scanning electron microscopy (SEM), the eggs and larvae were fixed for $6 \mathrm{~h}$ in $4 \%$ glutaraldehyde buffered with phosphate buffer saline ( $\mathrm{pH}$ 6.8). They were then dehydrated in a graded ethanol series, replaced with isoamyl acetate twice for 30 min respectively, dried in a $\mathrm{CO}_{2}$ criti- cal point dryer, sputter-coated with gold, and observed under a Jeol JSM6360LV SEM at $15 \mathrm{kV}$.

\section{Results}

\subsection{Adults (Figs. 1a-b)}

The original description of adult $P$. qinlingensis Chou \& Ran is in Chou et al. (1981). Here a brief description is provided for the integration of its life cycle.

Male (Fig. 1a): Body yellowish brown, 10.0 $11.2 \mathrm{~mm}$ long. Wingspan $21.1-22.8 \mathrm{~mm}$. Forewings hyaline with dark brown markings. Apical band broad. Pterostigmal band broad and complete, with a broad basal branch and an interrupted distal branch. Marginal spot large, slightly beyond the vein $\mathrm{R}_{3+4}$. Basal band complete. Hind wings similar to forewings except basal band largely constricted at posterior part. Abdominal segment VI without anal horn. Genital bulb slightly rounded. Epandrium $\left(9^{\text {th }}\right.$ tergum $)$ with a broad U-shaped distal emargination. Hypovalves broad and divergent. Gonostyli short, with a small mesal process and a large basal cup. Ventral parameres long, slender and curved, bearing hairs along outer margin of distal part.

Female (Fig. 1b): Body 10.3-11.8 mm long. Wingspan 21.5-23.3 mm. Wing pattern similar to 

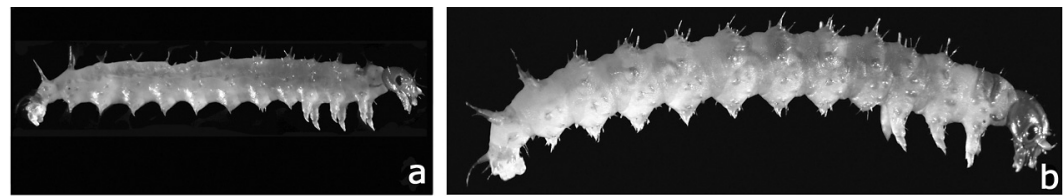

Fig. 2. Larvae and pu-

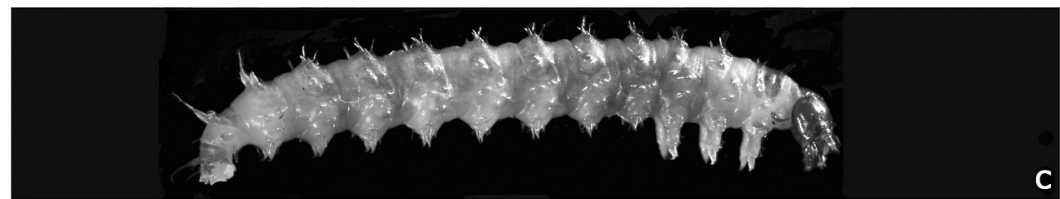
pae of $P$. qinlingensis. - a. First instar larva. - b. Second instar larva. - c. Third instar larva. - d. Fourth instar larva. - e. Male pupa. $-\mathrm{f}$. Female pupa.
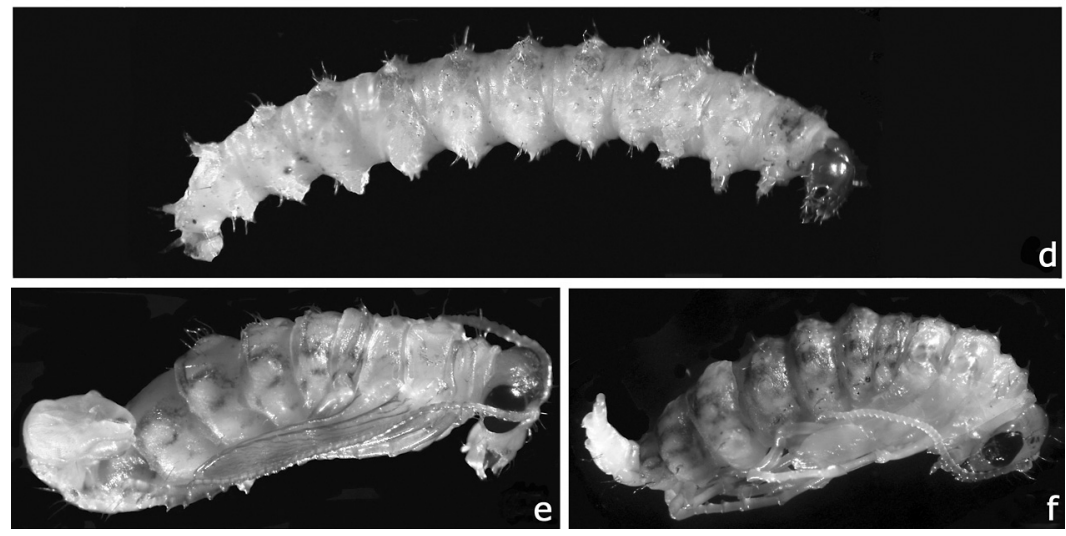

male except the apical branch of pterostigmal band narrower and the basal band interrupted. Subgenital plate broad at base and gradually narrowing toward apex from middle part. Genital plate with prolongation of apical plate wider, acute, and deeply U-shaped emarginated; axis extending beyond the genital plate by a third of its length.

\subsection{Egg (Figs.1c-d)}

The egg is oval in shape, about $1.0 \mathrm{~mm}$ long and $0.7 \mathrm{~mm}$ wide. The freshly laid eggs are milky white and turn yellowish brown in several hours (Fig. 1c). The chorion is covered with irregular polygonal network (Fig. 1d), which is distinctive from its congeners (unpublished observation). Upon hatching, the reddish mandibles and compound eyes of the larvae are visible through the somewhat translucent chorion.

\subsection{Larva (Figs. 2a-d)}

The larva is eruciform, four instars. The head is hypognathous. A pair of prominent compound eyes are present on the lateral side of head. Antennae are 3-segmented. Thorax has three pairs of 4segmented legs, which resemble each other in structure. Abdominal segments I-VIII each possesses a pair of short prolegs. Abdominal segments I-IX each bears a pair of dorsal annulated setae, which are conspicuously longer and fingerlike on segments VIII and IX. The $10^{\text {th }}$ abdominal segment bears only one middorsal annulated seta. The spiracles are present on prothorax and the first eight abdominal segments.

\subsubsection{First instar larva (Fig. 2a)}

Newly hatched larva is $3.0 \mathrm{~mm}$ long, generally grayish white with eyes and mandibles reddish brown (Fig. 2a). Width of head capsule is 0.49 $\mathrm{mm}$.

The head is highly sclerotized (Figs. 2a, 3cd). The egg burster, a sharp projection, with which the larva ruptures the eggshell during hatching, is located near the ventral margin of frons (Fig. 3a, d). The compound eye consists of over 25 facets (Figs. 3a, c), but the exact number of facets is hard to count in newly hatched larvae 

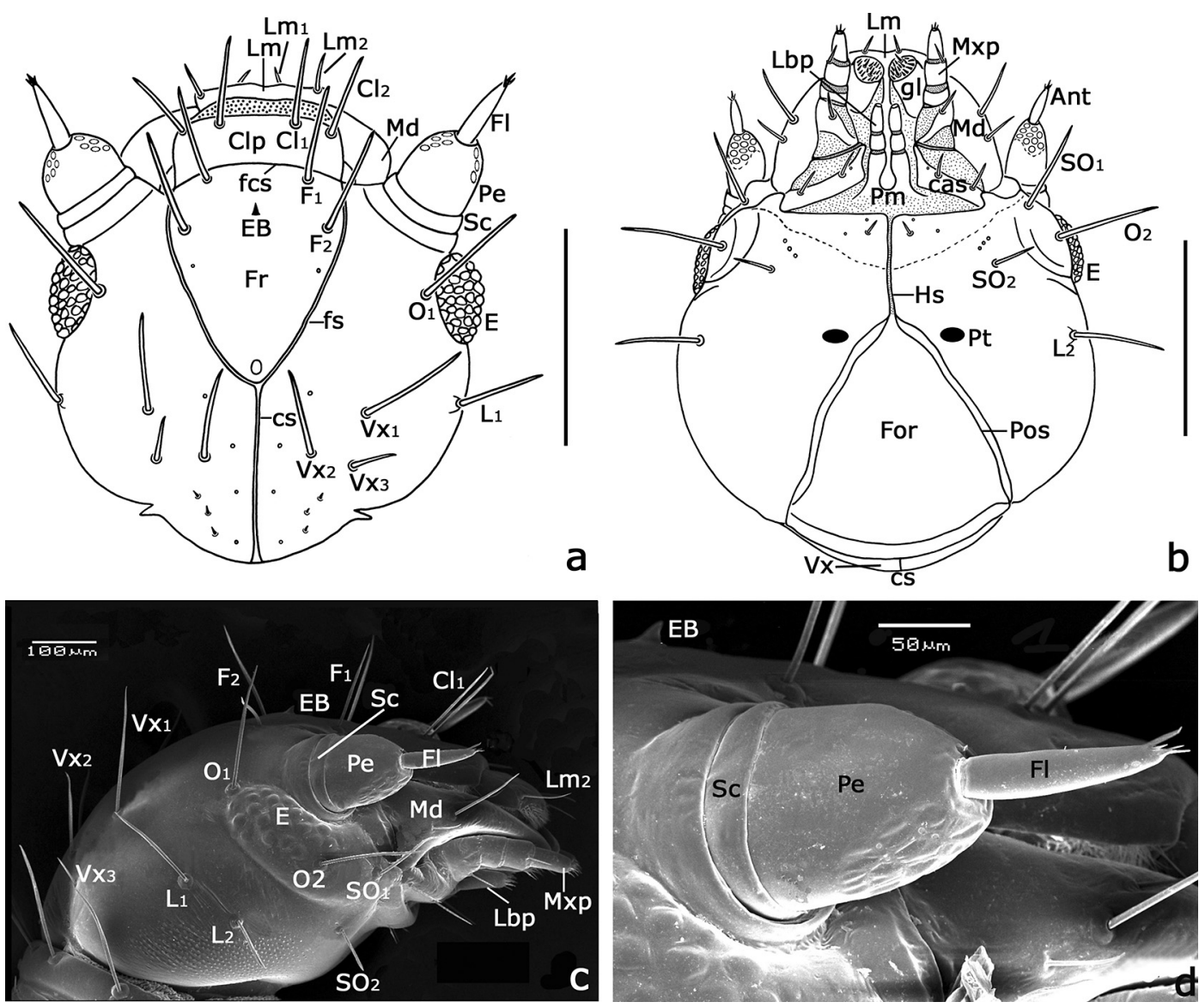

Fig. 3. Head of $P$. qinlingensis larva. - a. Head of first instar larva, dorsal view. $-b$. Head of fourth instar larva, ventral view. - c. Head of first instar larva, lateral view. - d. Antenna of first instar larva. Ant, antenna; cas, cardostipes; CL1-2, clypeal setae; Clp, clypeus; cs, coronal suture; E, compound eye; EB, egg burster; fcs, frontoclypeal suture; Fl, flagellum; For, occipital foramen; Fr, frons; fs, frontal suture; gl, galea; Hs, hypostomal suture; L1-2, labral setae; Lbp, labial palp; Lm, labrum; Md, mandible; Mxp, maxillary palp; 01-3, ocular setae; Pe, pedicel; Pm, prementum; Pos, postoccipital suture; Pt, posterior tentorial pit; Sc, scape; SO1-2, subocular setae; $\mathrm{V} x 1-3$, vertical setae. Scale bar for $a=0.25 \mathrm{~mm}$; scale bar for $b=0.5 \mathrm{~mm}$.

under light microscopy. At the dorsomost corner of frons is a lustrous round spot, probably being the remnant of the median ocellus.

The antenna is 3-segmented, lying between the eyes and close to the base of each mandible (Fig. 3a, c, d). The basal scape is very short and stout, inserted into the membranous antennal socket reinforced by the antennal sclerites. The pedicel is very thick, subconical in shape, with 24 cup-like sensory pits arranged in two opposed groups on dorsal and ventral sides near its apex. The flagellum is slender and finger-like, as long as the pedicel, with four to six peg-like apical setae.
The mouthparts is of typical mandibulate type (Figs. 3c, 4a-d). The labrum is trapezoid, proximally linking with the anterior margin of the welldeveloped clypeus, which is sclerotized in basal area and membranous in apical area (Fig. 3a). The ventral margin of the labrum is slightly notched medially with numerous minute hairs and two pairs of long setae, the outer pair twice as long as the inner pair (Fig. 4a). The epipharynx bears numerous short hairs, a prominent median sclerite connecting labrum with anterior clypeus (Fig. 4a).

The mandible is dark reddish brown and heavily sclerotized, articulated with the head cap- 


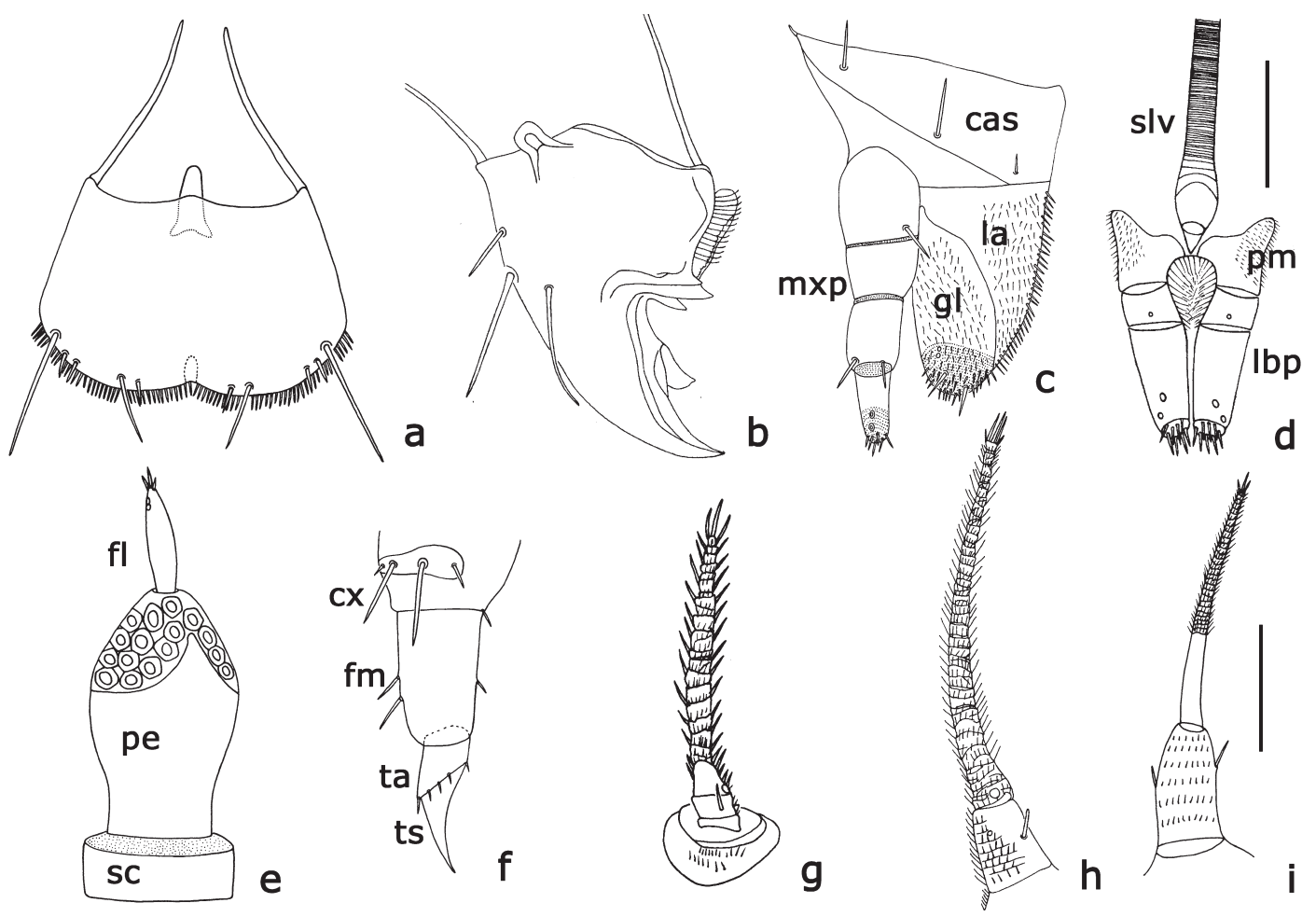

Fig. 4. Larva of $P$. qinlingensis. a-d, mouthparts of first instar larva. - a. Labrum, dorsal view. - b. Left mandible, ventral view. $-c$. Left maxillae, ventral view. $-d$. Labium, ventral view. - e. Antenna of fourth instar larva. $-f$. Prothoracic leg of first instar larva. - g. Annulated seta on 4th abdominal segment of first instar larva. $-h$. Annulated seta on 9th abdominal segment of first instar larva. - i. Annulated seta on 9th abdominal segment of fourth instar larva. cas, cardo-stipes; cx, coxa; fl, flagellum; fm, femur; gl, galea; la, lacinia; lbp, labial palp; mxp, maxillary palp; pe, pedicel; pm, prementum; sc, scape; slv, salivary duct; ta, tibia; ts, tarsus. Scale bar of a-d $=0.2 \mathrm{~mm}$; scale bar of $\mathrm{e}-\mathrm{i}=0.1 \mathrm{~mm}$.

sule by two condyles (Fig. 4b). It curves inward and tapers toward apex like a three-sided pyramid. Two long and one short seta lie medially on the smooth outer surface. The incisor region bears four strong shearing cusps, one mesal and three basal cusps. The molar region is covered with uniform, dense hairs.

The maxillae are smaller than the mandibles. The lacinia and the galea fuse into a broad fleshy lobe with numerous minute hairs (Fig. 4c). The stipes seems to fuse with the cardo, resulting into a cardo-stipes, with two long and one short seta. The maxillary palp is 4-segmented, with the basal joint slightly thicker and the distal joint slender. The basal joint bears one apical seta, and the third joint has two apical setae. The distal joint is rounded apically with six short apical setae and two sensory pits.

The labium is greatly reduced in size, with ligula absent. Most parts of the labium are retracted into the capsule, only a pair of 2-segmented palps are erected from the basal, mesially separated prementum between the cardo-stipes bases of the paired maxillae. The distal segment is slender, at least twice as long as the basal segment, with several short apical setae (Fig. 4d).

The principal setae of the larval head (Figs. $3 \mathrm{a}, \mathrm{c})$ are grouped in six sets. There are two pairs of frontal setae $\left(\mathrm{F}_{1}\right.$ and $\left.\mathrm{F}_{2}\right)$, situated along the frontal suture and associated with a pair of frontal punctures. Two pairs of clypeal setae $\left(\mathrm{Cl}_{1}\right.$ and $\mathrm{Cl}_{2}$ ) are present near the anterior margin of clypeus. At the dorsal and ventral margins of the eyes are a pair of ocular setae $\left(\mathrm{O}_{1}\right.$ and $\left.\mathrm{O}_{2}\right)$. Further back and in a triangle are three pairs of vertical setae $\left(\mathrm{Vx}_{1}, \mathrm{Vx}_{2}\right.$ and $\left.\mathrm{Vx}_{3}\right)$ and four pairs of vertical punctures on each side of the vertex. Posterior to the eyes, and generally at the same level, are two 

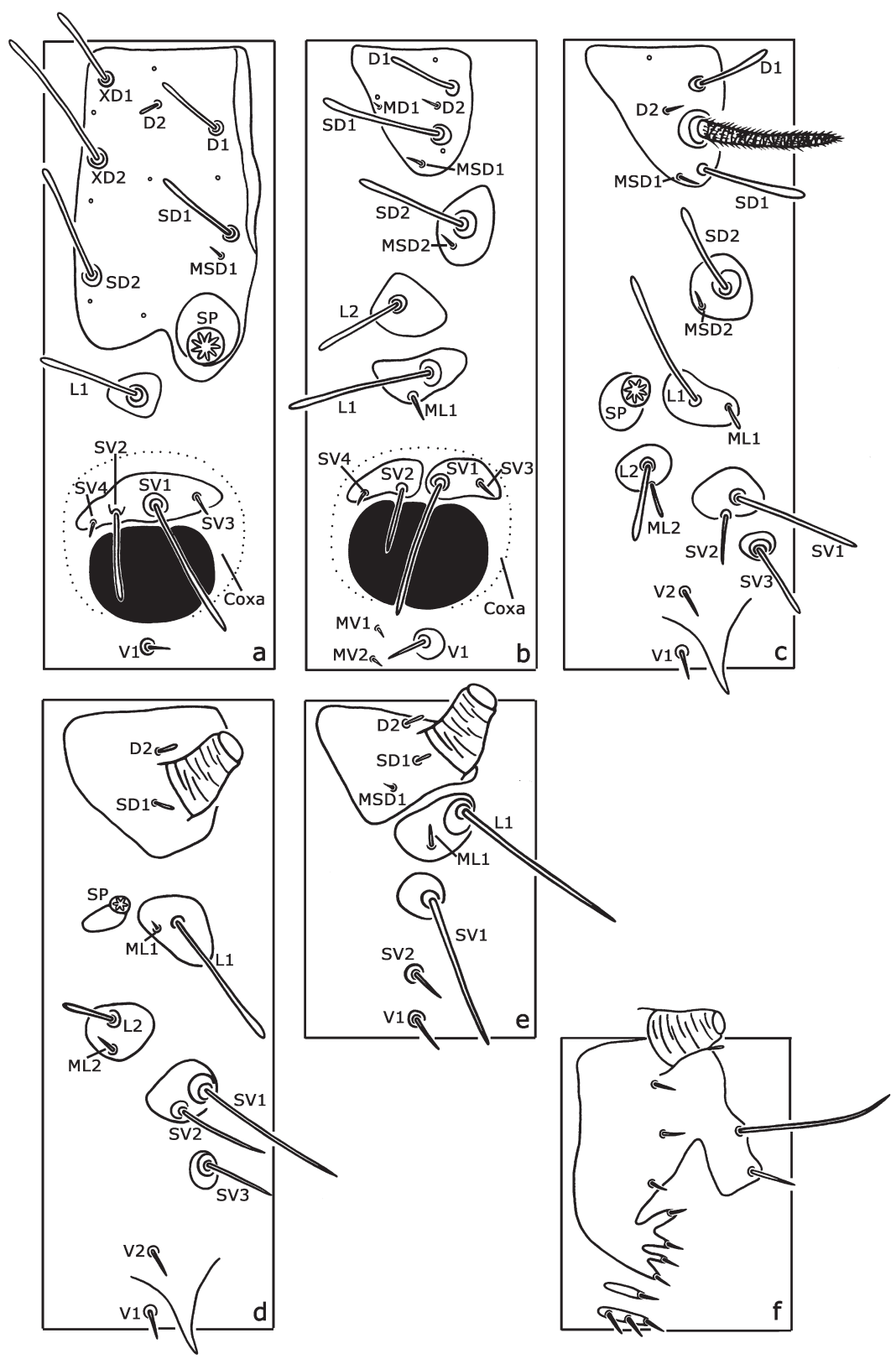

Fig. 5. Chaetotaxy of first instar larva of $P$. qinlingensis. $-a$. Prothorax. - b. Mesothorax. - c. First abdominal segment. - d. Eighth abdominal segment. - e. Ninth abdominal segment. $-f$. Tenth abdominal segment. D1-2, dorsal setae; L1-2, lateral setae; MD1, minute dorsal seta; MSD1-2, minute subdorsal setae; ML1-2, minute lateral setae; MV1, minute ventral seta; SD12, subdorsal setae; SP, spiracle; SV1-4, subventral setae; $X D, 1-2$ prothoracic setae; $\mathrm{V} 1-$ 2, ventral setae [Setal abbreviations follow Hinton (1946)].

pairs of lateral setae $\left(\mathrm{L}_{1}\right.$ and $\left.\mathrm{L}_{2}\right)$. Below the eyes are two pairs of subocular setae $\left(\mathrm{SO}_{1}\right.$ and $\left.\mathrm{SO}_{2}\right)$.

The primary setae of the thorax and abdomen are of two kinds, the long and usually tactile setae and the minute or proprioceptor setae. The most setae of the first instar larva, including the long and the minute setae, are generally clavate (Figs. $6 \mathrm{c}-\mathrm{d})$. On the prothoracic shield there are six primary tactile setae, two of which (XD1 and XD2) do not occur on the other segments. The other four, the two dorsal setae (D1 and D2) and the two subdorsal setae (SD1 and SD2) are also present on the meso- and metathorax and abdominal segments I-VIII.

The prothoracic shield is very large and somewhat quadrate, with three long setae (XD1, XD2 and $\mathrm{SD}_{2}$ ) and two punctures roughly in line along the anterior margin; two long and a very short seta (D1, SD1 and MSD1) and a puncture are along the posterior margin; a short seta (D2) lies be- 
Fig. 6. First instar of $P$. qinlingensis, SEM. - a. Abdominal prolegs, lateral view, dorsum to left. $-b$. First abdominal spiracle. - c. Annulated seta and clavate setae on abdominal segment VII. - d. Proximal part of the annulated seta on abdominal segment IX.
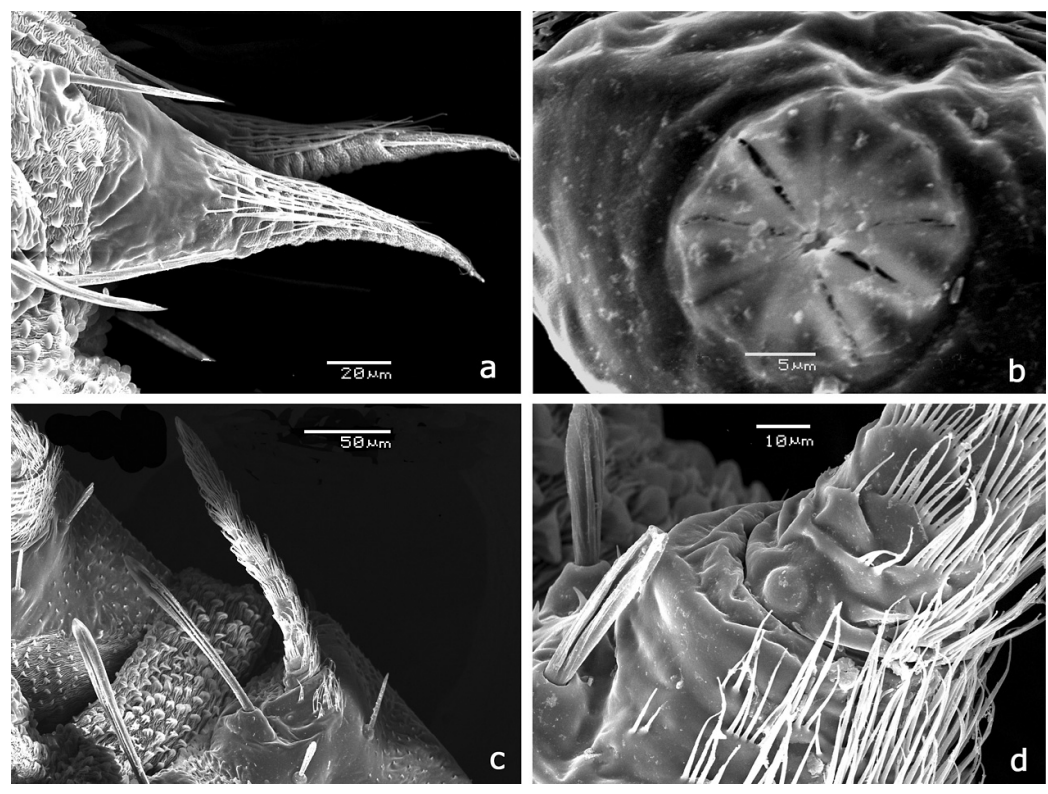

tween XD1 and D1 (Fig. 5a). The spiracle is located at the posterolateral corner of the shield, nearly circular in form, with 9-11 apertures. The atrial orifice is very simple with a rounded central portion. Below the ventral margin of the shield is a long lateral seta (L1) on a rounded pinaculum anterior-ventral to the spiracle. On a crescentshaped pinaculum dorsal to the leg cavity are one long, two median and one short seta (SV1-SV4). Only a single short ventral seta (V1) is present on sternum near the midventral line between legs. Thoracic legs are 4-segmented: the basal coxa swollen, the femur elongated and sclerotized with three setae, tibia with four setae on the distal ridge among numerous hairs, and the terminal tarsus hook-like and tapering toward apex (Fig. 4f).

Meso- and metathorax (Fig. 5b) are similar to each other in chaetotaxy with six pinacula. The dorsal pinaculum has two long clavate setae (D1 and SD1), one short seta (D2), two minute setae (MD1 and MSD1) and three punctures. The subdorsal pinaculum bears a long seta (SD2) and a minute seta (MSD2). Spiracle is absent from meso- and metathorax. Two lateral pinacula bear a long and a short seta (L1, L2, ML1 and ML2) respectively, sometimes ML2 is missing. On both of the prominent subventral pinacula are a long and a short seta (SV1-SV4). Beside V1 on the ventral area are two short minute setae (MV1 and MV2). The meso- and metathoracic legs are quite similar to prothoracic legs (Fig. 2a).

The abdomen consists of 11 segments with the first seven being very similar to each other in structure and chaetotaxy, each bearing a pair of lateral spiracles and a pair of ventral prolegs (Fig. $5 \mathrm{c})$. The abdominal spiracles resemble the thoracic ones, generally composed of 5-7 apertures, but the first abdominal spiracle usually is larger than the rest in diameter with 8-9 apertures (Figs. $5 \mathrm{c}, 6 \mathrm{~b})$. The prolegs are transversely wrinkled and covered with many rows of hairs, terminating at a single claw-like structure (Fig. 6a). A pair of prominent, suberect, annulated setae are present on the dorsal pinaculum of segments I-IX (Figs. $4 \mathrm{~g}, 5 \mathrm{c}$ ), bearing many palm-like hairs (Figs. 6cd). On the dorsal pinaculum are also two long and two short setae (D1, D2, SD1 and MSD1) (Fig. 5c). A long and a short seta (SD2 and MSD2) are on the subdorsal pinaculum. A lateral pinaculum posterior to the spiracle bear a long and a short seta (L1 and ML1), and another lateral pinaculum ventral to the spiracle possesses a long and a short seta (L2 and ML2). On two subventral pinacula are three long setae (SV1-SV3). Two ventral setae (V1 and V2) are present on both sides of ventral prolegs.

Abdominal segment VIII (Fig. 5d) is similar to the proceeding seven segments, also bearing a pair of prolegs and a pair of spiracles, but the annulated dorsal seta is much longer and born on 
a subconical, fleshy lobe or protuberance (Fig. 4h). The dorsal pinaculum has only two short setae (D2 and SD1). On two lateral pinacula are a long and a short seta (L1, ML1; L2, ML2). Three subventral setae (SV1-SV3) are on the subventral pinacula. On each side of the proleg lies a ventral seta (V1, V2).

Abdominal segment IX (Fig. 5e) is much thinner than the eighth abdominal segment, but bears the longest paired dorsal annulated setae (Fig. 4h). Spiracles and prolegs are absent. The dorsal pinaculum bears three short setae (D2, SD1 and MSD1). On the lateral pinaculum are a long and a short seta (L1 and ML1). A long subvental seta (SV1) is present on a pinaculum, and another short seta (SV2) is without pinaculum. The single ventral seta (V1) is near the midventral line.

Abdominal segment $\mathrm{X}$ (Fig. 5f) is a short and cylindrical segment. It has neither prolegs nor spiracle. The most peculiar character of this segment is that it possesses only a single middorsal annulated seta distinctly protruding from a large pilose process on the tergum. A single long and several short setae are hard to homologize. A pectinate structure composing of four digital processes is present on the lateral side, each process terminating with a short seta.

Telson is fleshy, conspicuous and quadrifurcate, surrounding the anus (Fig. 2a). There are no prolegs on this segment.

\subsubsection{Second instar larva (Fig. 2b)}

After the first molt, the larva changes prominently in appearance. The most noticeable change is the marked reduction of the annulated setae, especially those on the first seven abdominal segments. The second instar larvae are translucent at first, but soon become pale yellowish white. The larva is $5.51 \mathrm{~mm}$ long with head capsule $0.52 \mathrm{~mm}$ wide. The width of head capsule is comparatively smaller than that in the first instar. The legs are less prominent. In addition, the clavate setae found in the first instar transform into ordinary setae, becoming sharp at apex. The spiracles increase a little in their aperture number and diameter.

\subsubsection{Third and fourth instar larvae}

(Figs. 2c-d)

The third and fourth instar larvae are 7.83 and $13.64 \mathrm{~mm}$ long, with the width of head capsule 0.93 and $1.25 \mathrm{~mm}$ respectively. General appearance of the larva changes little from the second to third instar. The third and fourth instar larvae only represent a continuation of trends seen in the second instar. However, the antennal flagellum is much shorter, only corresponding to half the length of pedicle, which has about 28 sensory pits (Figs. 3b, 4e). The facets of the compound eyes are well defined. In the fourth instar, the spiracles have about 30 apertures and the atrial orifice is Tshaped. The annulated setae of abdominal segments VIII-X change markedly in form from the previous instars, becoming much shorter and less prominent (Fig. 4i).

\subsection{Pupae (Figs. 2e-f, 7)}

The pupa is exarate and decticous, light creamcolored at first, then turning whitish ochreous, eventually close to adults in appearance. The body curves in S-shape with a hypognathous head and the last three abdominal segments curve upward. The compound eyes are very prominent, occupying most of the head, brownish black with reddish tinge. The antennae are filiform with 37 40 joints. The pedicel bears five setae in female and seven in male. At the early stage of pupa, the mouthparts resemble those of larva except the lacinia and galea are differentiated. The maxillary palps are 5-segmented. The labium is well developed. Upon emergence, the pupa finally acquires the same mouthparts as adult. Three ocelli are arranged in a triangle on the anterior vertex and top corner of frons, but no sign of them is left on the pupal shell after emergence.

The body trunk nearly takes the shape of adult except that all the setae are longer than those of larvae. Pronotum bears three setae in male (Fig. 7a), four in female. Meso- and metathorax have three setae both in male and female. The wing sheath extends to the middle of the fifth abdominal segment. In male terga I-IX bear 4, 6, 6, 6, 2, 1, 2, 0 and 1 seta respectively (Figs. 7b-d). Female setae on terga are generally similar to those 

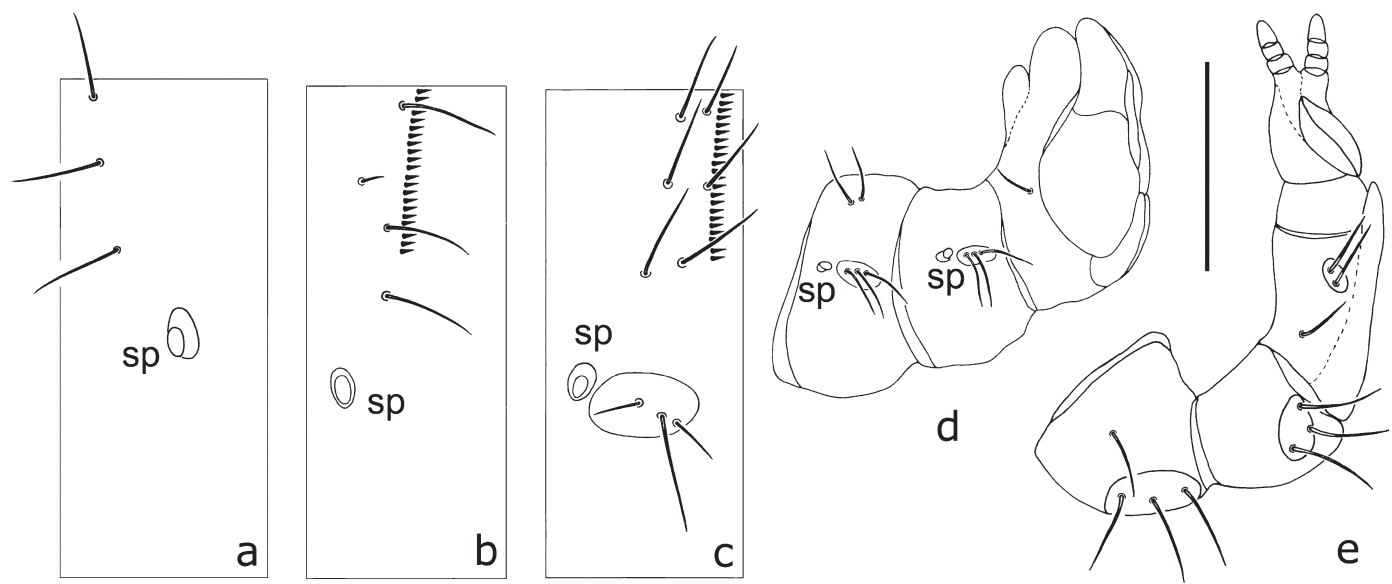

Fig. 7. Chaetotaxy and terminal abdomen of pupa of $P$. qinlingensis. a-d, male. $-a$. Prothorax. $-b$. First abdominal segment. - c. Third abdominal segment. - d. Caudal abdominal segments. - e. Caudal abdominal segments of female. Sp, spiracle. Scale bar $=0.3 \mathrm{~mm}$.

in male except tergum $\mathrm{V}$ with only one instead of two setae. Behind spiracles three lateral setae are arranged roughly in a straight line (Figs. $7 \mathrm{c}-\mathrm{d}$ ). In both sexes, the first three abdominal segments possess a transverse row of short thick spines, which are situated in the middle part on segment I (Fig. 7b) and near posterior margin on segments II and III (Fig. 7c). The sex of a pupa can be readily recognized from the terminal abdominal shape. In male abdominal segment IX expands distinctly into a genital bulb (Fig. 7d). In female abdomen tapers gradually from the 7th to 9th segment, ending with a pair of 2-segmented cerci (Fig. 7e).

\section{Biology}

Panorpa qinlingenis is a bivoltine insect, completing two generations per year in the Micang Mountain and overwintering as prepupal stage in the soil. In the next spring, the overwintered scorpionflies pupate from mid April to late May. The adults emerge from pupae mainly from mid May to early June for the overwintering generation, and from late July to mid August for the first generation. There appear two population peaks in the field, one at early June and the other at early August. Usually, the scorpionflies are not visible in the field after early September.

Male and female adults generally begin to copulate about one week after emergence. Four to eight days after copulation, females begin to deposit eggs in clusters into crevices of the soil. Each female lays 35 to 180 eggs in her lifetime. Both adults and larvae feed on katydids, grasshoppers, and caterpillars when reared in captivity. Feeding activity occurs mostly during the day, mating in the afternoon.

The duration of the egg stage usually lasts for five to nine days, hatching from midnight to early morning (23:00 to 6:00). The young larva normally utilizes its egg burster on frons to rupture the eggshell to emerge out of the egg. Some larvae fail to emerge and eventually die during hatching process. Most of the larvae that fail to hatch come out of the egg with abdomen first, instead of using the egg burster. The newly hatched larvae consume the chorion of their own and the other weak infertile eggs in the cluster as their first food items, then scatter to search for other food and the hidden quarters. The larva usually burrows an earth cell under its food, lying on its back within the cell. The stadia from the first to fourth instar of the first generation are 4-5, 4-6, 5-7 and 6-9 d respectively. When fully grown, the fourth instar larvae become inactive, preparing to pupate. The pupal stage of the first generation last for 8-18 days.

\section{Discussion}

The first instar larva bears an egg burster on the frons close to the fronto-clypeal suture. This 
structure was also noticed by Byers (2002), but overlooked by other earlier researchers such as Miyake (1912) and Mampe and Neunzig (1965). On the top corner of the larval frons there exists a lustrous round spot, which we suspect is probably the remnant of the reduced median ocellus since there is a definite median ocellus at the corresponding position of larval frons in Bittacidae (Tan \& Hua 2008, Setty 1940). However, this needs to be further confirmed.

In the Japanese Panorpa klugi MacLachlan, the antennae were described as four joints and labial palps 3-jointed (Miyake 1912), which might be incorrectly counted. In $P$. qinlingensis the larval antennae are clearly 3 -segmented (Figs. 3c-d, 4e), which is also noticed by Byers (1963) in $P$. nuptialis Gerstaecker and the 2-segmented labial palps are situated on the medially separated prementum (Figs. 3b, 4d).

For the larvae, Miyake (1912) recognized seven instars judged from head width. Through rearing, we found that the larvae have only four instars in Panorpa qinlingensis. Four instars seem to be the normal situation in Panorpa, since Byers (1963) also observed four instars in the larvae of Panorpa nuptialis.

Yie (1951) provided detailed description and illustration for several species of Panorpa. He claimed that the forms of the larval setae afford useful characters for the identification among genera as well as groups and species. In $\mathrm{NeO}-$ panorpa the setae are usually short and gradually enlarged from their bases to form rounded knobs, while in Panorpa the setae are long and slender, with the apices not so enlarged (Yie 1951). Yie (1951) adopted the setal nomenclature of Fracker (1915). In this paper, we first apply the more common nomenclature of chaetotaxy proposed for lepidopterous larvae by Hinton (1946) into the nomenclature of the chaetotaxy in Panorpidae.

The pupal chaetotaxy was also found to be useful for species identification. In Panorpa qinlingensis, a row of short thick spines were found on the first three abdominal segments, seeming to support Byers (1963) argument that the spines might be a useful taxonomic character.

Anyway, since there is only limited number of species in Panorpidae whose immature stages have been investigated, more related studies are desperately needed.
Acknowledgements. We wish to thank the staff in the Liping National Forest Park for their kind helps during our collecting and rearing the scorpionfly. This research was financially supported in part by the National Natural Science Foundation of China (grant no. 30070101 \& 30670255) and by the Ministry of Science and Technology of China (MOST grant no. 2006FY120100).

\section{References}

Boese, A. E. 1973: Descriptions of larvae and key to fourth instars of North American Panorpa (Mecoptera: Panorpidae). - University of Kansas Science Bulletin 50: 163-186.

Brauer, F. 1863: Beitrage zur Kenntniss der PanorpidenLarven. - Verhandlungen der kaiserlich-koniglichen zoologisch-botanischen Gesellschaft in Wien 13: 307-324.

Byers, G. W. 1963: The life history of Panorpa nuptialis (Mecoptera: Panorpidae). - Annals of the Entomological Society of America 56: 142-149.

Byers, G. W. 2002: Scorpionflies, hangingflies, and other Mecoptera. - Kansas School Naturalist 48: 1-15.

Cai, L. J., Li, J. \& Hua, B. Z. 2006: Life history of the scorpionfly Panorpa qinlingensis in Qinling Mountains of Shaanxi. — Chinese Bulletin of Entomology 43: 681683.

Chou, I., Ran, R. B. \& Wang, S. M. 1981: Study on the classification of the Chinese Mecoptera (I, II). - Entomotaxonomia 3: 1-22.

Fracker, S. B. 1915: The classification of lepidopterous larvae. - Illinois Biological Monographs 2: 1-69.

Hinton, H. E. 1946: On the homology and nomenclature of the setae of lepidopterous larvae, with some notes on the phylogeny of the Lepidoptera. - Transactions of the Royal Entomological Society of London 97: 1-37.

Mampe, C. D. \& Neunzig, H. H. 1965: Larval descriptions of two species of Panorpa (Mecoptera: Panorpidae) with notes on their biology. - Annals of the Entomological Society of America 58: 843-849.

Miyake, T. 1912: The life-history of Panorpa klugi MacLachlan. - Journal of the College of Agriculture, Imperial University, Tokyo 4: 117-139.

Setty, L. R. 1940: Biology and morphology of some North American Bittacidae (Order Mecoptera). — The American Midland Naturalist 23: 257-353.

Shiperovitsch, V. J. 1940: Biology and life cycle of Panorpa communis L. - Review Russe d'Entomologie 19: 27-40.

Tan, J. L., Hua, B. Z. 2008: Morphology of immature stages of Bittacus choui (Mecoptera: Bittacidae) with notes on its biology. - Journal of Natural History 42: 2127-2142.

Yie, S. T. 1951: The biology of Formosan Panorpidae and morphology of eleven species of their immature stages. - Memoirs of the College of Agriculture, National Taiwan University 2(4): 1-111. 